Research Article

\title{
Factors Contributing to Employability in Agriculture Department as Perceived by the Diploma Holders
}

\author{
Muhammad Tariq Chaudhary ${ }^{1}$, Saleem Ashraf ${ }^{2}$, Muhammad Yaseen ${ }^{3}$ and Muhammad Luqman ${ }^{3}$ \\ ${ }^{1}$ Adaptive Research Farm, Sheikhupura Punjab, Pakistan; ${ }^{2}$ In-Service Agriculture Training Institute Rabim Yar Khan, Pun- \\ jab, Pakistan; ${ }^{3}$ University College of Agriculture, University of Sargodha, Pakistan.
}

\begin{abstract}
This study explored some notable factors contributing to the employability in agriculture department, Government of the Punjab as perceived by the Diploma in Agricultural Sciences (DAS) holders. who were recruited in agriculture department during 2017. This study was quantitative and data were collected through questionnaire from 300 respondents who were recently appointed as Field Assistants (FAs) in Agriculture Department. Total 237 questioners returned by the respondents were found complete, thus, sample size was reduced to 237. Effective Schools Model presented by Lezotte (2010)" was employed as theoretical framework of this study. Collected data were analyzed through Statistical Package for Social Sciences (SPSS). Results unveiled that average age of respondents was 25.03 years. Maximum respondents (31.96\%) had received DAS from IATI, Sargodha while least contribution came from University of Agriculture Faisalabad (2.86\%). Family background of $77.45 \%$ respondents was rural and farming was key source of income for more than half of respondents (56.14\%). Satisfaction with classroom facilities (Mean=2.47 \pm 0.67 ), higher grades in examination (Mean=2.39 \pm 0.77 ) and relevance of the coursework (Mean=2.38 \pm 0.75 ) learned at training institutes helped respondents to get through the recruitment process. Regression analysis affirmed that extracurricular activities $(\mathrm{P}<0.05)$, being a sportsman, $(\mathrm{P}<0.01)$, higher grades in examination $(\mathrm{P}<0.05)$, educational environment at IATI Sargodha $(\mathrm{P}<0.01)$ and Rahim Yar Khan $(\mathrm{P}<0.05)$ were the prominent determinants of their employability. Study concludes that educational activities and co-curricular activities were equally important for the successful academic performance and earning an employability. Study stresses to streamline extracurricular activities at institutes level and conductance of inter and intra institutes competitions to bring positive change in behavior of students to pave the way towards success.

Received | July 15, 2019; Accepted | December 30, 2020; Published | April 09, 2021

*Correspondence | Saleem Ashraf, In Service Agricultural Training Institute Rahim Yar Khan, Pakistan; Email: saleem1828@gmail.com

Citation | Chaudhary, M.T., S. Ashraf, M. Yaseen and M. Luqman, 2021. Factors contributing to employability in agriculture department as perceived by the diploma holders. Sarbad Journal of Agriculture, 37(2): 419-427.

DOI | https://dx.doi.org/10.17582/journal.sja/2021/37.2.419.427

Keywords | Employability, Academics, Training, Examination, Grades, Behavior
\end{abstract}

\section{Introduction}

A gricultural education is central to bring changes to the behavior of end users towards the innovation. Agricultural graduates are considered of key importance in order to disseminate information among rural communities for the desired positive change. Therefore, to enrich the agriculture sector with qualified staff, a comprehensive system of formal agricultural education persists in Pakistan. University level education offers agricultural degrees in various disciplines is prominent example of agricultural education system working in Pakistan. Research and agriculture extension are major pillars of agriculture. Former concerns with technology development while later is mainly responsible for dissemination of these 
technologies among farmers. Agriculture Extension operates under Secretary of Agriculture and Director General Agriculture (Extension and Adaptive Research) on provincial level in the Punjab. Deputy Director of Agriculture (Extension), Assistant Director of Agriculture (Extension), Agriculture Officer (AO), Field Assistant (FA) perform duties on district, tehsil, markaz and union council level, respectively. Field Assistant is helping hand of Agriculture Officer in order to undertake effective extension activities on markaz level. The entire core group is mainly focused on bring positive change in behavior of farmers to foster adoption of innovations (Ashraf et al., 2019).

The eligibility criteria for the selection as Field Assistant (FA) is three-year Diploma in Agricultural Sciences (DAS) followed by the qualifying written test and interview that is conducted by the Punjab Public Service Commission (PPSC). In this regard, Government of the Punjab has established various agricultural training institutes across the province. In-Service Agricultural Training Institute, Sargodha (1961-62) and Rahim Yar Khan (1952-53) and Rawalpindi (1978-79) are foremost institutes (Government of the Punjab, 1996). Agriculture Training Institute, Karo Lal Eson, Layyah is latest addition among training institutes. This diploma enables students to understand farmers' needs and shape their abilities to perform working in the field. Students are imparted with practical trainings to meet farmers need. Effective commination skills of diploma graduates help them to bridge communication gap.

Diploma graduates serve as front line extension workers in agricultural extension and research wings. They further contribute in private and semi government firms to execute advisory services. Across Pakistan, there is no system of agricultural education on primary and secondary level, therefore, training institutions are pivotal in promoting agriculture among young blood and equipping them with skills of convincing farmers to adopt modern technologies (Akhtar et al., 2018). Valuing this diploma, University of Agriculture Faisalabad (UAF) also initiated Diploma in Agricultural Sciences at main campus.

Employability is associated with various attributes. Enhanced motivation (Fingerut et al., 2013), deep learning (Cappelleri and Vitoroulis, 2012), technical learningandawareness toresearch(Mitchelletal.,2011), control over learning (Fingerut et al., 2013) academic writing (Battisti et al., 2010), interdisciplinary and intra-disciplinary work (Fingerut et al., 2013), student to faculty interaction (Regueras et al., 2010) and skill development are key factors weighing employability. Regueras et al. (2010) affirmed that conducive and competitive learning escalates confidence, motivation and academic performance of students. Learning pedagogy reinforced by effective teaching techniques improves confidence among students and their grades ultimately. Multidisciplinary competition improves students' academic performance, understanding to course contents and persuasion to qualify interview for job (Shehata, 2015). Karanja et al. (2015) cemented that employment is highly influenced by academic performance.

This research study was planned to investigate those factors contributing in employment as Field Assistant. This research further study aimed at unveiling determinates of successful selection as Field Assistant as perceived by recently appointed Field Assistants.

\section{Significance of research}

Scientific research on various disciplines of agriculture across Pakistan is abundant. However, social research focusing on agricultural education is scanty so far. Very few research studies are focused on finding those factors which play vital role in successful employment. This kind of research in agriculture sector is particularly negligible. In true sense, these research studies can give a deep insights and future discourse to focus on particular subjects and bridge gaps persisting across the training institutes in Punjab. This research is significant being foremost in focusing on recently appointed Field Assistants in Agriculture Department. This study aimed to explore those factors which played significantly in successful employment. It is anticipated that findings of this research will provide guidance and roadmap to agriculture training institutes to formulate plan of work in order to improve the educational standards that can pave the way for the successful induction of students in agriculture department in future.

\section{Theoretical framework}

This research study was based upon "Effective Schools Model by Lezotte (2010). This Model implies that effective educational institution/school is that which can demonstrate the existence of quality and equity and student's achievement can be measured. 
According to Lezotte (2010) effective schools possess some prominent correlates including, instructional leadership, concise and focused mission, security, anticipation of success, monitoring of progress of the students, opportunities to learn and positivity in home-school relations. Model further augmented that, instructional leadership build team work, environment of conducive learning and professional development among students. Learning activities undertaken at institutions are meaningful and significant in improving knowledge of students. Interactive learning environment developed at institution builds parity among students and honor within society. Students' family background does have pivotal contribution in academic performance. This academic performance further paves the way towards success in getting job. Students have equal opportunities of development and success regardless of their gender, age, sect and socio-economic conditions (Lezotte, 2010).

This theory was assumed relevant to this research where factors contributing in employment as field assistant. Though, IATIs are genuinely training institute but motive is to educate students for their wellbeing. Hence, idea of institute of school is not different. These training institutes offer formal education with well-equipped conducive learning environment and instructional facilities. This motive is in line with those of Sullivan and Glanz (2000) where they asserted that offering instructional facilities to bring change in behavior is the vision of school or institution.

In this research contributing factors listed in questionnaire were screened through literature of relevant research papers and about 16 factors were enlisted to record the perceptions of recently appointed Field Assistants.

\section{Materials and Methods}

To prepare trained field force for department of extension 05 In-Service Training Institutes are working. These 05 training institutes are, In-Service Agricultural Training Institute (IATI), Sargodha, In-Service Agricultural Training Institute (IATI), Rahim Yar Khan, Barani Agricultural Training Institute, Rawalpindi, Agriculture Training Institute (ATI), Karor lal Eson Layah and Agriculture Training Institute Garhi Dupata, Murree. Collateral to these mentioned institutes, University of
Agriculture Faisalabad and Pak-German polytechnic Institute, Chak 5 Faiz, Multan are also offering DAS for matriculate students. Major purpose of these institutes is to produce Field force (Field Assistants) and conduct short training courses for agricultural officers and officials.

In 2017, about 500 posts of Field Assistants were advertised by Punjab Public Service Commission under administration of Government of the Punjab, Agriculture Department.

A vast number of students applied for the said posts. After written test and interview about 300 Field Assistants successfully qualified for the post of Field Assistant. Later on, selected officials were deployed in different Union Councils of the different districts across the Punjab. All the applicants and selected FAs had completed Diploma in Agricultural Sciences from above stated institutes. So, these selected Field Assistants were the targeted respondents for this study. It was not an easy to contact each selected FA as they were deployed in entire province.

For the first time, Government of the Punjab, advised IATIs to organize induction training for the selected FAs. Hence, All IATIs, organized induction training for the officials deployed in areas under jurisdiction of each institute, regardless from which institute they completed their diploma. These induction trainings rendered an opportunity to target selected FA in these trainings. It was decided to consult maximum respondents to identify which factors played significant role in their success.

Researcher obtained the training schedule of IATIs to plan process of data collection accordingly. For the data collection instructors of each institute cordially coordinated with researchers.

Questionnaire was prepared in accordance of the objectives of the study. To enlist factors contributing in success, extensive literature was reviewed and about 16 factors were listed in questionnaire. Threepoint likert scale reflecting 1 for low, 2 for medium and 3 for high contribution was used to assess the extent of contribution. Questionnaire was validated through content validity technique and pre-tested on 20 respondents other than sample. Questionnaire was pre-tested on students enrolled in DAS at IATI, Rahim Yar Khan. After pre-testing questionnaire 
was finalized and administered to respondents. Questionnaires were sent to instructor of each IATI and requested to administer questionnaires to FAs. Instructions were rendered to corresponding instructor of institutes. Respondents were further provided with brief instructions to fulfill questionnaire by the corresponding instructors.

Questionnaire was administered to all participants of the induction trainings held at different institutes and all questionnaires were returned by the participants. However, while reviewing filled questionnaires, 13 questionnaires were found incompletely filled or left blanked. Total 237 completely filled questionnaires were considered as sample size for this study.

Collected data were codded in excel sheet and later on transformed to SPSS for analysis. Descriptive as well as inferential statistics was applied for in depth analysis. Frequency, percentages and mean values were calculated while logistic regression was applied to unveil the relationship.

\section{Empirical model}

Perceptions are perspective and site specific owed to persisting heterogeneity in factors having tendency to influence them like family background, education, age, income, and various institutional factors (Maddison, 2007; Deressa et al., 2011). This research followed binary logistics regression model to explore those factors which influenced successful selection of job. In this model, dependent variable is dichotomous in nature taking a value of 1 or 0 . Although the Ordinary Least Squares (OLS) method may compute estimates for the binary choice models, certain assumptions of the classical regression model will be violated. These include non-normality of disturbances, heteroscedastic variances of the disturbances, and questionable value of $\mathrm{R}^{2}$ as a measure of goodness of fit (Gujarati, 2003). For instance, given:

$$
v i=b 0+b i c i+e i
$$

Where; vi= 1 if a student is successful in getting job vi $=0$ if a student does not, b0 is intercept, biis parameter to be estimated, ci is variable in question, and ei is disturbance term. This model is a typical linear regression model, but because the regression is binary or dichotomous, itis called a linear probability model (LPM). However, in a regression model, when the dependent variable is dichotomous in nature, taking value 1 or 0 , use of linear probability models becomes a major problem. This is because predicted value can fall outside the relevant range of zero to one probability value. Thus, if linear probability models are used, results may fail to meet statistical assumptions necessary to validate conclusions based on the hypothesis tested (Feder et al., 1985).

Gujarati (2003) recommended Logit and probit models to overcome the problem associated with LPM. These models use Maximum Likelihood Estimation (MLE) procedures and ensure that probabilities are bound between 0 and 1 . Both logit and probit transformations estimate cumulative distribution, thereby eliminating the interval 0, 1problem associated with LPM. The logistic cumulative probability function can be represented by:

$$
P=F(Z i)=\frac{1}{1+e^{-z i}}
$$

Where $\mathrm{P} i$ is the probability that $\mathrm{i}^{\text {th }}$ person will be in I - first category, $\mathrm{Zi}=\mathrm{b} 0+$ bici + ei where b0 is intercept of the model; bi is model parameters to be estimated; ci are the independent variables and e represents base of natural logarithms, which is approximately equal to 2.718. In Equation 2, $\mathrm{Z}$ can range from positive infinity to negative infinity. The probability of a farmer perceiving climate change lies between 0 and 1 . If we multiply both sides of the Equation 2 by $1+$ e-zi we get:

$$
\left(1+e^{-z i}\right) P i=1
$$

Dividing by $\mathrm{P}$ and then subtracting 1 lead to:

$$
e^{-z i}=\frac{1}{P i}=\frac{1-P i}{P i}
$$

By definition; however, e-zi $=1$ / e-zi so that the Equation 4 becomes.

$$
e^{-z i}=\frac{P i}{1-P i}
$$

By taking the natural logarithm of both sides of Equation 5, we get:

$$
Z i=\log \left(\frac{P i}{1-P i}\right)
$$

In other words: 


$$
\log \left(\frac{P i}{1-P i}\right)=Z i=\beta o+\beta i X i
$$

This makes the logistic probability model.

Therefore, it can be noted that the logistic model defined in the Equation 7 is based on the logits of $Z$, which constitutes the stimulus index. Marginal effects can also be computed to show changes in probability when there is a unit change in independent variables. Marginal effects are computed as:

$$
\frac{\partial P k}{\partial x k}=\frac{\beta k e^{-z k}}{\left(1+e^{-z k}\right)^{z}}
$$

Therefore, this logistic regression model was used to determine those factors, which influenced farmers' perception on climate change. The dependent variable is farmers' perception of climate change, a binary variable indicating whether or not a farmer has perceived climate change. It was regressed on a set of relevant explanatory variables hypothesized based on literature to have influence on perception to climate change. Using these variables, the model is specified as:

$$
Z i=(\beta i X i)+\varepsilon i \quad \ldots(9)
$$

Where;

$\mathrm{Zi}$ is the perception by the $\mathrm{i}^{\text {th }}$ respondent that job can be achieve, ci is the vector of explanatory variables of probability of receiving job by the $\mathrm{i}^{\text {th }}$ respondent, bi is the vector of the parameter estimates of the regressors hypothesized to influence the probability of respondents' perception job selection.

\section{Definition of variables}

The major variables expected to have influence in successful selection of job is explained below:

The dependent variable of the study: In this research study student's success in getting job was the dependent variable. This implies that selection in job is attributed to high grades, completion of diploma, confidence, appearing in interview and defacing himself in the best entrust of job requirement. Selection in job is dummy variable takes 1 when the respondents get job and 0 otherwise.

The explanatory/ independent variables: The independent variables that are hypothesized to contribute in job selection are combined effects of various factors like high grades, physical health, family background, involvement in co-curricular activities, being sportsman, instructional quality, personal experience in farming and experience of job in private sector.

\section{Ethical issues}

For ethical purposes, respondents were free to not disclose information they did not wish to share. They also got the opportunity to refuse any question which they felt uncomfortable answering. Therefore, the relationship with the respondents during the survey was professional but comfortable. In addition, in the analysis and reporting, identification of respondents (such as real name) was kept confidential.

\section{Results and Discussion}

Table 1 shows that the mean age of respondents was 24.03 years. All respondents were Diploma in Agricultural Sciences (DAS) holders from different training institutes of the Punjab. Interestingly, ample respondents were having additional qualification along with diploma. For instance, 8.19\% respondents had completed F.A and $4.09 \%$ respondents were B.A along with DAS. Of the total respondents, 31.96\% respondents passed out from In-service Agricultural Training Institute, Sargodha followed by substantially greater than one fourth respondents $(28.68 \%)$ who were passed out from In-service Agricultural Training Institute, Rahim Yar Khan. The percentage of passing outs from Agriculture Training Institute (ATI) Karor, Multan and University of Agriculture Faisalabad stood as $4.50,9.42$ and $2.86 \%$ respectively. Of total respondents, $77.45 \%$ belonged to rural and $22.54 \%$ had urban family background. Farming appeared as prominent income source $(56.14 \%)$ as compared to non-farming (43.85\%). This implies that respondents were young, energetic and educated enriched with plenty of rural area awareness to uplift farming endeavors. potentially, these young field assistants could understand the needs of farmers and undertake field activities in befitting manner.

Table 2 arbitrates that majority of respondents (64.75\%) got job in Department of Agriculture, Government of the Punjab amid 1-5 years of completion of their DAS course. These respondents were considerably fresh graduates of different institutes. Conversely, 31.96\% respondent got an opportunity to join agriculture department between 
6-10 years after completion of their DAS course. Of the total respondents, $3.27 \%$ respondents cemented their joining after more than ten years of diploma completion. This implies that job opportunities for the Diploma holders in agriculture department are scanty and infrequent. Amid informal discussion, respondents argued that agriculture department advertised Field Assistant jobs for diploma holders after a decade. Though, the induction process should remain continue frequently. This situation indicates misery and prevalent unemployment among diploma holders. As a result, half of the respondents served private sector for income generation while rest managed their agriculture farms.

Table 1: Demographic attributes of the respondents.

\begin{tabular}{llll} 
Demographic attributes & F & $\%$ & Mean \\
Age & & & 25.03 \\
Education & & & \\
DAS & 244 & 100 & \\
DAS+FA & 20 & 8.19 & \\
DAS+BA & 10 & 4.09 \\
Institute name & & & \\
IATI Sargodha & 78 & 31.96 \\
IATI Rahim Yar Khan & 70 & 28.68 \\
BATI Rawalpindi & 55 & 22.54 & \\
ATI Karor & 11 & 4.50 \\
Multan & 23 & 9.42 \\
University of Agriculture Faisalabad & 7 & 2.86 \\
Family Background & & \\
Rural & 189 & 77.45 \\
\hline Urban & 55 & 22.54 \\
\hline Income Source & & \\
Farming & 137 & 56.14 \\
Non-Farming & 107 & 43.85 \\
\hline
\end{tabular}

When asking about involvement in co-curricular activities held at institutes, $64.3 \%$ notarized their involvement while $35.7 \%$ answered in negative. Respondents pointed their involvement in sports activities, debates, speech competitions, managerial competitions and other inter and intra institutes competitions. Among total respondents, 53.6\% confirmed regular involvement in sports. These sportsmen students argued that participation in inter and intra institutes games competition. Moreover, these students were regular players of the institute having significant contribution in keeping sports grounds alive.

Table 2: Perception of respondents.

\begin{tabular}{lll} 
After how much years you got job? & f & $\mathbf{\%}$ \\
\hline $1-5$ years & 158 & 64.75 \\
$6-10$ & 78 & 31.96 \\
\hline More than 10 & 08 & 3.27 \\
\hline Average Years & 4.43 & \\
\hline Prior Job did you ever served private sector? & $\mathrm{f}$ & $\%$ \\
\hline Yes & 123 & 50.4 \\
\hline No & 121 & 49.6 \\
Were you part of co-curricular activities at & $\mathrm{f}$ & $\%$ \\
institute? & & \\
Yes & 157 & 64.3 \\
\hline No & 87 & 35.7 \\
Were you a regular sportsman? & $\mathrm{f}$ & $\%$ \\
Yes & 131 & 53.6 \\
No & 113 & 46.31
\end{tabular}

Table 2 explores different factors contributing in selection as perceived by the respondents. Of the numerous factors, satisfaction of respondents with classroom facilities was the foremost factor $($ Mean $=2.47 \pm 0.67)$. This implies that classroom management and class room facilities available for the students in training institutes were effective and conducive for students learning.

Table 3: Factors perceived by respondents contributing in their success.

\section{Factors}

High grades in academic activities/DAS

Off-campus relations with teachers

Active participation in sports activities

Involvement in extra-curricular activities

Family Background (i.e. educated family)

Strong financial position of family

Experience from private sector

Personal farming experience

Staying in hostel

Quality of instructions

Relevance of coursework

Satisfaction with classroom facilities

Institutional rules and management

Spirituality

Part time job

Physical Health

Conducive class room environment offers effective learning opportunities to students and gives them
Mean \pm SD Rank

$2.39 \pm 0.77 \quad 2$

$2.21 \pm 1.04 \quad 5$

$1.50 \pm 1.16 \quad 12$

$2.16 \pm 0.86 \quad 6$

$1.82 \pm 1.05 \quad 9$

$1.44 \pm 1.07 \quad 14$

$2.06 \pm 1.12 \quad 7$

$1.60 \pm 1.29 \quad 11$

$1.62 \pm 1.00 \quad 10$

$1.85 \pm 1.20 \quad 8$

$2.38 \pm 0.75 \quad 3$

$2.47 \pm 0.67 \quad 1$

$1.45 \pm 1.26 \quad 13$

$2.21 \pm 0.95 \quad 5$

$2.35 \pm 0.67 \quad 4$

$1.92 \pm 1.21 \quad 8$ 
an opportunity to learn and explore their potential. Learning further cements higher grades and academic performance. Higher grades and academic performance are inevitable to compete for getting a job. Higher grades in academic activities was perceived $2^{\text {nd }}$ leading factor $($ Mean $=2.39 \pm 0.77$ ) having significant contributing in getting a job. Amid discussion, majority of the respondents unveiled that conducive learning environment maintained by instructional staff during lectures was the key behind higher grades. Relevance of coursework was perceived $3^{\text {rd }}$ leading contributor $($ Mean $=2.38 \pm 0.75$ ) in job selection. Respondents appreciated the contents of courses taught during entire diploma course. Respondents perceived during discussion that, course regarding crop production, plant protection, extension education and information technology were facilitative and well in need of field work.

It has been widely stated in demographic section that more than half respondents were from rural background and reliance for income on non-farming was escalating. Hence, to meet basic needs student did part time job. The part time working was $4^{\text {th }}$ leading contributing factor (Mean=2.35 \pm 0.67 ). followed by spirituality grabbing $5^{\text {th }}$ rank. Respondents illustrated that, part time job gave us an experience and enthusiasm to work hard in order to secure future.

Involvement in extracurricular activities appeared $6^{\text {th }}$ leading factor helping in successful selection of job (Mean=2.16 \pm 0.86$)$. Respondents were involved in various inter and intra institute games competition, debate and speech competition and managerial activities. This involvement improved confidence of the respondents and enhanced sense of responsibility and discipline. Rafiullah et al. (2017) reported alteration in behavior of students in result of involvement in extra-curricular activities. Brown (2010) augmented that involvement in extracurricular activities enhances self-esteem and confidence of students.

Job in private sector was another significant factor perceived by the respondents with mean value of $2.06 \pm 1.12$, having profound role in getting selection. During informal debate, respondents stated that working with private sector particularly in pesticide companies improved their technical knowledge and the ability of public dealing. Working with private sector gave them the opportunity of practical learning which helped them to get through the interview.
Contribution of other listed factors stood less than 2.00. This implies that contribution of these factors in job selection was of less than medium level. Active participation in sports activities, Institutional rules and management and strong financial position of family were the least factors contributing to the selection as perceived by the respondents.

Table 4: Logistic regression indicating impact of various factors on successful job selection.

\begin{tabular}{|c|c|c|}
\hline Factors & $\begin{array}{l}\text { B (coeffi- } \\
\text { cients) }\end{array}$ & $\begin{array}{l}P \\
\text { value }\end{array}$ \\
\hline Being part of co-curricular activities & $0.210^{*}$ & 0.007 \\
\hline Being sportsman & $0.399^{* *}$ & 0.005 \\
\hline Income & -0.249 & 0.639 \\
\hline High grades in academic activities/DAS & $0.515^{*}$ & 0.034 \\
\hline Off-campus relations with teachers & 0.231 & 0.464 \\
\hline Active participation in sports activities & $0.403^{*}$ & 0.098 \\
\hline Involvement in extra-curricular activities & 0.086 & 0.727 \\
\hline Family Background (i.e. educated family) & -0.218 & 0.389 \\
\hline Family Background (i.e. educated family) & 0.170 & 0.498 \\
\hline Strong financial position of family & -0.182 & 0.387 \\
\hline Experience from private sector & $-0.162^{*}$ & 0.044 \\
\hline Personal farming experience & 0.075 & 0.762 \\
\hline Staying in hostel & -0.178 & 0.415 \\
\hline Quality of instructions & -0.350 & 0.331 \\
\hline Relevance of coursework & 0.043 & 0.902 \\
\hline Satisfaction with classroom facilities & 0.158 & 0.635 \\
\hline Institutional rules and management & -0.232 & 0.493 \\
\hline Spirituality & -0.384 & 0.313 \\
\hline Part time job & 0.028 & 0.905 \\
\hline Physical Health & $-0.579^{*}$ & 0.064 \\
\hline \multicolumn{3}{|l|}{ Institutes } \\
\hline Sargodha & $1.507^{* *}$ & 0.000 \\
\hline Rahim Yar Khan & $1.795^{*}$ & 0.092 \\
\hline Rawalpindi & -1.341 & 0.451 \\
\hline Karor & 1.440 & 0.355 \\
\hline Multan & 24.360 & 1.000 \\
\hline UAF & -9.388 & 0.980 \\
\hline Constant & -1.692 & 0.504 \\
\hline
\end{tabular}

*significant level 5\%; **ignificance level 1\%.

Table 4 is the illustration of logistic regression findings. Selection in job was the dependent variable while other contributing factors as perceived by the respondents were kept as independent variables. Results indicated significant association of co-curricular activities with the selection for job $(\mathrm{P}<0.05)$. Conversely, being sportsman was highly significant with the selection for 
the job $(\mathrm{P}<0.01)$. This implies that involvement in $\mathrm{co}^{-}$ curricular activities and sports competitions perhaps escalated the confidence among students which could have paved the way towards their success. Findings are similar to those of Howie et al. (2010) as they found significant impact of co-curricular activities on academic performance of students. Findings infer that age 15-22 years is the age of learning and involving students in extra-curricular activities improves students' performance as they remain under supervision and guidance of teachers and coaches. Cosdenet al. (2012) unveiled that students who had participation in extra-curricular activities, had three times more significant academic performance as compared to those who didn't participate. Significant impact of extracurricular activities on academic performance was also reported by (Daniyal et al., 2012). Lau et al. (2014) inferred that involvement in extra-curricular activities influences the employability of students. High grades in examination stood significant with selection for job $(\mathrm{P}<0.05)$. Higher grades improve academic performance and influence job interviews (Ming, 2005).

Physical health of respondents was found significantly associated with selection for job. Negative beta coefficient value implies that, with the decreasing physical health, chances of selection for job may decrease. However, the positive notion appeared that students' involvement in c-curricular activities and sports activities was the key to sound physical health. Of the total institutes, IATI, Sargodha, appeared highly significant $(\mathrm{P}<0.01)$ in playing important role in selection of job. While IATI, Rahim Yar Khan exhibited significant association with $(\mathrm{P}<0.05)$ selection for job. This infers that institutes have pivotal role in development of students and preparing them for the competitions. This doesn't imply that other institutes were not playing role in development of students. The difference stays because of available facilities, infrastructure and instructional staff. For instance, among institutes IATI Sargodha is prominent in infrastructure and faculty staff of more than twenty officers. Similarly, at IATI, instructional facilities are better supported with instructional staff of more than ten officers. Among other institutes, facilities are bit lower than these two institutes.

\section{Conclusions and Recommendations}

Study concluded that higher grades in examination, satisfaction with class room environment and quality of instructions are important for employability. However, these factors in isolation are insufficient for success. Role of extra-curricular activities, sportsmanship and physical health is equally important which is usually ignored at institutes' level. Study summarized that students enrolled in Das are usually of less than 20 years indicating young and productive age. This young age offers an extensive opportunity of learning. For effective learning it is imperative to integrate c-curricular activities with conducive learning environment and quality of instructions. Involvement in extra-curricular activities will rise students' confidence and give them an insight to learn through social experiences. Ultimately, students' vision will be broader. It is highly recommended to foster learning process, there is dire need to streamline extracurricular activities at institutes' level. Competitions on inter and intra-institute level could be most viable option to streamline student's confidence.

\section{Novelty Statement}

Diploma in Agricultural Sciences (DAS) and the Field Assistants are never brought under discussion in literature. This study is the true representation of the deprived section of extension field staff. The recommendations should be adopted by the training institutes in order to improve the competencies of the students enabling them to harvest more employment opportunities.

\section{Conflict of interest}

The author have declared no conflict of interest.

\section{References}

Akhtar, K., M.I. Yousuf and Q.Parveen. 2018. Possibilities of agricultural education for secondary level in Pakistan. Glob. Soc. Sci.Rev. 3(4): 173186.

Ashraf, S., Z.Y. Hassan and I. Ashraf. 2019. Dynamics of agricultural extension services in $\mathrm{Pa}-$ kistan: A history of national performance. J. Anim. Plant Sci., 29(6): 1707-1717. https:// doi.org/10.33804/978.969.7850.02.0

Battisti, F., G. Boato, M. Carli and A. Neri. 2010. Teaching multimedia data protection through an international online competition. IEEE Trans. Educ., 54(3): 381-386. https://doi. org/10.1109/TE.2010.2061850 
Brown, J.D., 2010. Across the (not so) great divide: Cultural similarities in self-evaluative processes. Soc. Pers. Psychol. Compass, 4: 318-330. https://doi.org/10.1111/j.17519004.2010.00267.x

Cappelleri, D.J. and N. Vitoroulis. 2012. The robotic decathlon: Project-based learning labs and curriculum design for an introductory robotics course. IEEE Trans. Educ., 56(1): 73-81. https://doi.org/10.1109/TE.2012.2215329

Cosdent, M., G. Morrison, L. Gutierrez and M. Brown. 2012. The effects of homework programs and after-school activities on school success. Theor. into Pract., 43(3): 220-226. https:// doi.org/10.1207/s15430421tip4303_8

Daniyal, M., T. Nawaz, A. Hassan and I. Mubeen. 2012. The effect of co-curricular activities on the academic performances of the students: A case study of the Islamia University of Bahawalpur, Pakistan. Bulg. J. Sci. Educ. Policy, 6(2): 257-272.

Deressa, T.T., R.M. Hassan and C. Ringler. 2011. Perception of and adaptation to climate change by farmers in the Nile basin of Ethiopia. J. Agric. Sci., 149(1): 23-31. https://doi.org/10.1017/ S0021859610000687

Gujarati, D. 2003. Basic econometrics. New York: McGraw-Hill.

Feder, G., R.E. Just and D. Zilberman. 1985. Adoption of agricultural innovations in developing countries: A survey. Econ. Dev. Cult. Change, 33(2): 255-298. https://doi. org $/ 10.1086 / 451461$

Fingerut, J., K. Orbe, D. Flynn and P. Habdas. 2013. Focusing on the Hard parts: A Biomechanics Laboratory Exercise. Bioscene: J. Coll. Biol. Teach., 39(1): 10-15.

Gujarati, D.N., 2009. Basic econometrics, $5^{\text {th }}$ edition, Tata McGraw-Hill Education, New Delhi, India.

Howie, L.D., S.L. Lukacs, P.N. Pastor, C.A. Reuben and P. Mendola.2010. Participation in activities outside of school hours in relation to problem behavior and social skills in middle childhood. J. Sch. Health, 80(3): 119-125. https://doi. org/10.1111/j.1746-1561.2009.00475.x

Karanja, W. 2015. Effects of reading difficulties on academic performance among form three students in public secondary schools, Kiambu County, Kenya. MED thesis, Kenyatta University, Kenya.

Lau, H.H., H.Y. Hsu, S. Acosta and T.L. Hsu. 2014. Impact of participation in extra-curricular activities during college on graduate employability: An empirical study of graduates of Taiwanese business schools. Educ. Stud., 40(1): 26-47. https://doi.org/10.1080/03055698.201 3.830244

Lezotte, L. W. (2010). What effective schools do: re-envisioning the correlates. Indianapolis, IN: Solution Tree.

Maddison, D., 2007. The perception of and adaptation to climate change in Africa. Policy research working paper; No. 4308. World Bank, Washington, DC. https://doi.org/10.1596/18139450-4308

Ming C.Y., 2005. Job offers of multi-national accounting firms: The effects of emotional intelligence, extra-curricular activities, and academic performance. Account. Educ., 14(1): 75-93. https://doi. org/10.1080/0693928042000229707

Mitchell, R., Y.J. Dori and N.H. Kuldell. 2011. Experiential Engineering through iGEM. An undergraduate summer competition in synthetic biology. J. Sci. Educ. Technol., 20(2): 156-160. https://doi.org/10.1007/s10956-010-9242-7

Rafiullah, F. Zaman and J. Khan. 2017. Positive impact of extracurricular activities on University students in Lahore, Pakistan. Int. J. Soc. Sci. Manage., 4(1): 22-31. https://doi.org/10.3126/ ijssm.v4i1.16339

Regueras, L.M., E. Verdu, M.J. Verdu and J.P. de Castro. 2010. Design of a competitive and collaborative learning strategy in a communication networks course. IEEE Trans. Educ., 54(2):302-307.https://doi.org/10.1109/ TE.2010.2053933

Shehata, M.H., 2015. Co-curricular activities and their role in supporting experiential learning. Proceedings of the Canadian Engineering Education Association (CEEA). https://doi. org/10.24908/pceea.v0i0.5791

Sullivan, S. and J. Glanz. 2000. Supervision that improves teaching. Thousand Oaks, CA: Corwin Press. 